\title{
Influence of cigarette smoking on thyroid function, goiter formation and autoimmune thyroid disorders
}

\author{
Nikolaos Pontikides, Gerassimos E. Krassas \\ Department of Endocrinology \& Metabolism "PANAGIA" General Hospital, Thessaloniki, Greece
}

\begin{abstract}
Both smoking and thyroid dysfunction are frequent in the general population. Many studies have shown that cigarette smoking interferes with thyroid function and with the evolution of thyroid pathology (e.g. goiter formation and thyroid cancer development). Some studies have also suggested a significant correlation of Graves' hyperthyroidism and Graves' ophthalmopathy with the severity of smoking. In addition, cigarette smoking may reduce the effectiveness of some therapeutic modalities, such as orbital radiotherapy or high-dose systemic glucocorticoid administration for severe thyroid eye disease. Tobacco smoking seems to induce similar changes in thyroid function in the adult and the fetus. This review article discusses the effect of cigarette smoking on thyroid function and morphology as well as on thyroid autoimmunity.
\end{abstract}

Key Words: thyroid function, goiter, thyroid cancer, Graves' disease, Graves' ophthalmopathy, autoimmune thyroid disorders, cigarette smoking

\section{INTRODUCTION}

Cigarette smoking has multiple effects on thyroid function and thyroid volume. These include minor and probably physiologically unimportant alterations in thyroid hormones ${ }^{1-10}$ and thyrotropin concentrations ${ }^{1-9}$, central (thyroid) and peripheral antithyroid action ${ }^{11,12}$, thyroid gland stimulating or goitrogenic action ${ }^{1,2,4,13}$, carcinogenesis lowering properties ${ }^{14-23}$ and also actions that increase susceptibility to Graves' disease ${ }^{24,25}$ and especially the incidence and clinical severity of thyroid associated ophthalmopathy ${ }^{26}$. Finally, it seems that parental smoking may have deleterious effects on fetal thyroid secre-

Address correspondence and requests for reprints to: Prof. G E Krassas, MD, Chairman, Dept. of Endocrinology and Metabolism, Panagia General Hospital, N. Plastira 22, 55132 Thessaloniki, Greece, Tel/Fax. +30-310-447444 / Fax.+30-310-282476, E-mail address: krassas@the.forthnet.gr Received 17-11-2001, Revised 03-01-02, Accepted 10-03-02 tion and on thyroid function of some of these infants at one year of age $\mathrm{e}^{27,28}$. How smoking might affect thyroid economy is not completely understood. For the goitrogenic effect of smoking, thiocyanate has been implicat$\mathrm{ed}^{29}$. However, other smoke products might have central or peripheral antithyroid actions, thyrotropin lowering activities or immulogical effects, although it is not clear whether or not these latter actions play an important role in the pathogenesis of smoking related autoimmune disorders $^{3,7,30,31}$.

This article reviews current aspects of the role of cigarette smoking in thyroid function, goiter formation, the risk of thyroid cancer development and the incidence and severity of different autoimmune thyroid disorders.

\section{SMOKING AND THYROID FUNCTION}

Cigarette smoking has multiple, minor effects on thyroid function. Serum thyroxine (T4) levels remain un- 
changed $^{1-6}$ or are slightly elevated ${ }^{7,8}$, while serum triidothyronine (T3) levels may be increased ${ }^{2-4}$ or unchanged $^{2,5-8}$. Sepkovic et al $^{9}$ found reduced serum T3 and T4 levels in heavy smokers. Of course, terms like increase or decrease do not necessarily indicate abnormal levels. In most of the above studies, the total values of thyroid hormones were determined. In some, however, free thyroid hormone levels were also analyzed, (although indirectly taking into account $\mathrm{T} 3$ resin uptake), and no difference with smoking habits was detected ${ }^{2,6,7,9}$. Reverse $\mathrm{T} 3$ (rT3) was found to be reduced in smokers ${ }^{1,10}$, while in two other studies increased levels of rT3 were associated with increased levels of $\mathrm{T} 4$ and unaltered levels of $\mathrm{T} 3^{7,8}$. Finally, Hegedus et al in two analogous studies found no differences in total T3, T4 and free T3 levels ${ }^{2,6}$.

Thyrotropin stimulating hormone (TSH) levels were found to be decreased ${ }^{2,5-8}$ or unaltered ${ }^{1,3,4,9}$. Muller et al. ${ }^{11}$ however, found that among women with subclinical hypothyroidism, smokers had higher serum TSH levels, higher serum ratio of $\mathrm{T} 3$ to free $\mathrm{T} 4$, and also higher cholesterol and low-density lipoprotein cholesterol concentrations than non smokers ${ }^{11}$. In contrast, patients with overt hypothyroidism either smokers or non-smokers, had similar serum TSH and thyroid hormone levels ${ }^{11}$. These results do not indicate that smoking causes hypothyroidism, but that it may increase the severity of the effects of hypothyroidism ${ }^{12}$. These variable results may be due to the fact that the various studies are not directly comparable. Although they were conducted in smokers and non-smokers, there were significant differences in age, sex, body weight, cigarette smoking habits, time of abstinence from smoking, previous thyroid function status, presence of thyroid autoimmunity and finally iodide status, factors known to affect the thyroid hormone levels.

In regard to thyroglobulin $(\mathrm{Tg})$ levels, Christensen et $\mathrm{al}^{1}$ found that smokers had significantly higher levels of serum $\mathrm{Tg}$ in comparison to non-smokers or ex-smokers. Hegedus et $\mathrm{al}^{2}$ found the same results among smokers who were compared with individuals who had never smoked. They also found that $\mathrm{Tg}$ was positively correlated to the volume of the thyroid gland, with a higher correlation in smokers ${ }^{1,2}$. However, even if the goitrous subjects were excluded, in this study serum Tg levels remained higher among smokers, indicating that smoking has an independent thyroid stimulating effect ${ }^{1,2}$.

An interesting issue is the mechanism(s) by which cigarette smoking affects thyroid function. Thiocyanate (SCN-), a perchlorate like goitrogen, acts by preventing iodine and no difference with smoking habits were de- tected accumulation (trapping) by the thyroid. It is generated from cigarette smoke as a detoxifying product of cyanide. The levels of the SCN- in the blood are related to the amount of cigarette smoke inhalation ${ }^{3}$. SCN- competitively inhibits iodide uptake and hormone synthesis and increases iodide efflux from the thyroid cells ${ }^{30}$. This competitive inhibition of iodide transport may be important for understanding the action of SCN- in vivo. Iodine deficiency may enhance the antithyroid actions of $\mathrm{SCN}$ - and iodide excess may diminish the effect ${ }^{2,34}$.

Although nicotine in cigarette smoking does not influence iodide turnover ${ }^{30}$, it might cause sympathetic activation, which could increase thyroid secretion ${ }^{7,32}$. Alternatively, nicotine or other component(s) of tobacco smoking, such as benzpyrene, may have direct thyroid stimulatory actions or stimulating effects on hepatic oxidative metabolism, which in turn may stimulate hepatic conversion of $\mathrm{T} 4$ to $\mathrm{T}^{31}$.

\section{SMOKING AND GOITER FORMATION}

It is well known that many factors are involved in the regulation of thyroid volume. TSH levels, iodine concentration, the presence of thyroid autoimmunity and several goitrogens are generally accepted factors but others, such as sex, age, body weight or personal habits (e.g. cigarette smoking, alcohol abuse) are controversial in regard to their effect on thyroid volume.

As far as the goitrogenic effect of cigarette smoking is concerned, Christensen et $\mathrm{al}^{1}$ found an increased frequency of mainly multinodular goiter among middleaged heavy female smokers in comparison with ex-smokers, but not between smokers and people who had never smoked. Similar results were reported by Lio et $\mathrm{al}^{4}$ who demonstrated a higher frequency of multinodular goiter among heavy smokers. Ericsson et $\mathrm{al}^{13}$ also found increased incidence of goiter, either diffuse or multinodular. The latter was more common in the elderly. Hegedus et $\mathrm{al}^{2}$ using precise and accurate ultrasonic techniques ${ }^{34}$ showed that median thyroid gland volume was increased in smokers of both sexes by $73 \%$. Thyroid volume per body weight was also increased by $56 \%$ in smokers. Even when subjects with clinically detectable goiter were excluded, a significantly higher thyroid volume was found in those who were smokers ${ }^{2}$. On the other hand Petersen et $\mathrm{al}^{5}$ found no association between smoking and goiter frequency or differences in thyroid volume between smokers and non-smokers. Berghout et al ${ }^{35}$ failed to detect any correlation between thyroid volume and daily tobacco consumption (ranging from 5 to 15 cigarettes). 
In two more recent studies from the Netherlands and Italy, no difference was found in the smoking habits of patients with non-toxic goiter and those of healthy controls ${ }^{24,36}$. The above discrepancies are probably related to differences in the number of people examined, the age and sex of the study populations, the number of cigarettes consumed daily and the years of smoking, regional variations in dietary iodine intake, as well as variations in the methods used to assess thyroid size ${ }^{32}$ and even more, in the definition of goiter per $\mathrm{se}^{37}$. It is well known, for example, that differences exist when thyroid size is measured by palpation in comparison to the ultrasonic $\operatorname{method}^{37,38}$.

The goitrogenic action of smoking may be related to the goitrogenic effect of SCN- and probably other by products of smoke. The variation in the prevalence of goiter between different areas has been shown to be related to the level of urinary SCN- excretion ${ }^{39}$. Serum SCNlevels are elevated in cigarette smokers and have been used as a reliable indicator of smoking habits ${ }^{29}$. However, SCN- , which acts mainly by preventing iodine trapping, may not be a very important goitroitrogenic cofactor in iodine sufficient areas ${ }^{37}$.

\section{EFFECTS OF SMOKING ON THE RISK OF THYROID CANCER}

Relatively little is known about the pathogenesis and aetiology of thyroid cancer beyond its association with radiation exposure and some preexisting thyroid diseases, including endemic goiter, sporadic goiter, lymphocytic thyroiditis and Graves' disease ${ }^{40}$. During the last two decades, several studies have reported a reduced risk of thyroid cancer, mainly in women, albeit not always statistically significant, in association, with cigarette smoking ${ }^{14-21}$. However, only a few studies have addressed the effect of smoking on thyroid tumor in men ${ }^{16,22}$. Kreiger and Parkers recently explored the association of cigarette smoking with thyroid cancer in both sexes in a case-control study $^{23}$. Reduced risk was observed for ever/never cigarette smokers for both sexes with an odds ratio of 0.71 for females (95\% confidence interval $(\mathrm{CI})=0.60-0.83$ ) and 0.77 (95\% CI=0.58-1.02) for males. Dose-response effects were also observed in association with duration, quantity of cigarettes smoked and pack-years of exposure. There was no reduction in the protective effect associated with the age smoking was started or years since smoking was stopped. There was also evidence of reduced risk for all histological subgroups. Other investigators found similar although not always significant results in studies including only women ${ }^{14-16,20,21}$, except in two stud- ies which included men ${ }^{16,19}$. Rossing et $\mathrm{al}^{21}$ reported that a history of ever having smoked more than 100 cigarettes was associated with a reduced risk of thyroid cancer (odds ratio $0.7,95 \% \mathrm{CI}=0.5-0.9)$. This reduction in risk was most evident in current smokers (odds ratio 0.5, 95\% $\mathrm{CI}=0.4-0.7)$. Hallquist et $\mathrm{al}^{22}$ reported that both women who were previously smokers as well as current smokers had significantly decreased risks with odds ratio of 0.5 (95\% CI=0.2-0.96) and $0.6(95 \% \mathrm{CI}=0.3-0.96)$ respectively. Galanti et $\mathrm{al}^{20}$ reported a lower risk among young smokers, but no dose-response associated with the number of cigarettes or the number of years smoked. In contrast to the above mentioned studies, in a case-control study of 100 histologically verified thyroid cancer patients of both sexes and 100 matched controls, Sokic et $\mathrm{al}^{41}$ found no reduced risk of thyroid cancer in cigarette smokers.

Given that thyroid cancer occurs more frequently in women than in men, hormonal factors may also be involved in its pathogenesis. The mechanism (s) by which cigarette smoking may be protective for thyroid cancer is probably by lowering the endogenous levels of TSH $[1,8,13,42]$. It has been suggested that increased levels of $\mathrm{TSH}^{43}$ or elevated levels of other thyroid stimulators, as occurs during pregnancy, are associated with an increased risk of thyroid cancer ${ }^{15}$. Female preponderance of thyroid cancer has led to the hypothesis that estrogen metabolism may play a role in its pathogenesis. Indeed, it has been suggested by some studies that smoking may have an anti-estrogen effect ${ }^{44}$. However there is no evidence that smoking has similar effect(s) on androgen metabolism ${ }^{45}$.

\section{THYROID AUTOIMMUNE DISORDERS IN CIGARETTE SMOKERS}

\section{a. Graves' disease}

Graves' disease and Hashimoto's thyroiditis are the two main forms of so-called autoimmune thyroid disease (AITD). AITD is considered a polygenic, multifactorial disease which is characterized by activation of the immune system as a result of interactions between genetic predisposition and environmental factors ${ }^{46}$. The latter includes iodine intake ${ }^{47}$, seasonability, pollutants ${ }^{48}$ infections $^{49}$ and stressful life events ${ }^{50-52}$.

Cigarette smoking is an additional environmental factor which increases the risk for Graves' disease ${ }^{24,25}$. The interrelationship of Graves' disease and smoking has been detected in numerous studies. The mean prevalence of smokers in a European population of 709 patients with 
Graves' disease without relevant thyroid ophthalmopathy, extracted from seven studies, was $41 \%(22-56 \%)^{25,53}$. The percentage of smokers among 167 patients with Graves' disease without ophthalmopathy was $48 \%$, whereas the prevalence of smoking was $30 \%$ in patients with other thyroid disorders such as non-toxic nodular goiter, toxic nodular goiter and Hashimoto's thyroiditis $^{36}$. Similar results were found in two other case-control studie $^{24,54}$. The prevalence of smokers was $56 \%$ and $41 \%$ respectively in patients with Graves' disease and $41 \%$ and $30 \%$ in the control groups. The relative risk (RR) - odds ratio - was 1.9 and 1.4 respectively. Another study showed a prevalence of smokers of about $50 \%$ among hyperthyroid patients ${ }^{55}$. Shine et al on the other hand ${ }^{56}$, failed to confirm an increased prevalence of smokers among those with Graves' hyperthyroidism without relevant ophthalmopathy.

Until now, no definite mechanism has been provided for the influence of smoking on the prevalence of Graves' disease. In a recent review paper, Utige ${ }^{28}$ suggested that this might happen through different mechanisms, such as smoke-dependent structure alterations in TSH-receptor, making it more immunogenic, enhancement of responsiveness to factors responsible for the initiation of the disease or impairment of restoration of tolerance to thyroid autoantigens. Nevertheless, it has to be remembered that the nature of the disease may also influence smoking habits. It is well known that hyperthyroidism, when untreated, is associated with increased anxiety and nervousness and that uncontrolled psychosocial stress is associated with increased desire to smoke ${ }^{57}$.

\section{b. Graves'ophthalmopathy}

Graves' ophthalmopathy, or thyroid eye disease $(\mathrm{TED})^{58,59}$, is the most frequent extrathyroidal clinical manifestation of Graves' disease and constitutes a major and complex pathogenetic and therapeutic dilemma ${ }^{26}$. The first possible connection between cigarette smoking and Graves' ophthalmopathy was made by Hagg and Asplund $^{60}$ who showed that 10 out of 12 patients were current smokers, a figure much higher than that observed in Graves' patients without ophthalmopathy $(46 \%)$ or in control subjects $(31 \%)$. In addition, the prevalence of heavy smokers was higher in patients with more severe ophthalmopathy ${ }^{60}$. Since then, there have been several confirmatory reports in both retrospective and prospective studies. In a cross-sectional study reviewing the smoking habits of patients with different thyroid diseases, Bartalena et $\mathrm{al}^{36}$ found a $64 \%$ prevalence of smokers among patients with Graves' ophthalmopathy, a percentage much higher than that of Graves' disease without eye involvement (48\%), and 30\% in patients with nontoxic goiter, toxic nodular goiter and Hashimoto's thyroiditis. These results were confirmed by other investigators $^{13,24,36}$. The same group ${ }^{26}$ in a recent review paper estimated that the mean percentage of smokers among 732 patients with Graves' ophthalmopathy, compiled from 9 studies, was $67 \%$. This percentage of smokers is much higher than that in patients without Graves' ophthalmopathy ${ }^{53}$. Prummel et $\mathrm{al}^{24}$, in a consecutive entry case control study, found that smoking greatly increased the risk of Graves' ophthalmopathy, with odds ratio of 7.7 (95\% CI $=4.3-13.7)$. Furthermore, it seems that among patients with TED, smokers had more severe eye disease than non-smokers. No association has been found between the daily number of cigarettes consumed or the duration of smoking and the severity of TED ${ }^{25}$. Pfeilschifter and Ziegler ${ }^{61}$, in a recent prospective study, showed that smoking patients with recent onset of Graves' thyrotoxicosis had a 1.3-fold increased incidence of clinically relevant Graves' ophthalmopathy, with 2.6 and 3.1-fold increases in the incidence of proptosis and diplopia respectively. In the same study, it was found that the current number, but not lifetime cigarette consumption, was an independent risk factor for the development of TED. Finally, Teller et al showed ${ }^{62}$ that the prevalence of ophthalmopathy correlated not only with smoking but also with ethnic origin. The percentage of smokers was higher in Caucasians than in Asian patients (42\% and $7.7 \%$ respectively).

Smoking seems to influence not only the occurrence and the course of Graves' ophthalmopathy but also the response to various therapeutic interventions such as orbital radiotherapy and glycocorticoids administration ${ }^{63}$. Bartalena et $\mathrm{al}^{64}$ recently reported that in patients submitted to orbital radiotherapy and high-dose systemic glucocorticoid treatment for severe Graves' ophthalmopathy, a favorable response to treatment was observed in 61 of 65 non-smokers (94\%) and only in 58 of 85 smokers $(68 \%)$. Furthermore, among patients with mild Graves' ophthalmopathy, radioiodine treatment deteriorated eye disease in $0.5 \%$ of non-smokers and in $23 \%$ of smokers ${ }^{64}$. A concomitant short-term course of oral glucocorticoid therapy could prevent this progression ${ }^{65}$.

The etiology of endocrine ophthalmopathy is still unknown. The mechanism(s) of how cigarette smoking may affect the thyroid volume and especially the incidence and clinical severity of eye disease also remains unknown. Contents of cigarette smoke, hypoxia, formation of oxygen-free radicals ${ }^{66}$ or direct irritative actions of smoking ${ }^{14}$ have all been implicated in triggering the 
pathogenetic reaction of TED. Cigarette smoke is an irritant and can cause conjuctivitis and local irritation. This might not account, however, for the increase in volume of the extraocular muscles and/or of retrobulbar fibroadipose tissue. Smoking is also known to affect the immune system and autoimmunity is generally thought to play a role, although no specific ocular antigens have been identified as pathogens of TED. Hegedus et $\mathrm{al}^{6}$ found no differences in thyroid stimulating immunoglobulins (TSIS) among smoking and non-smoking healthy individuals. It is well accepted that cytokines play an important role in the pathogenesis of Graves' ophthalmopathy ${ }^{59,67,68}$. Cigarette smoking may affect this process because smokinginduced hypoxia in the retrobulbar tissue has been shown to increase the release of cytokines from orbital fibroblasts and endothelial cells ${ }^{69}$ and thereby may enhance the expression of adhesion molecules ${ }^{70}$. It has been reported that compared to non-smokers, smokers had lower circulating levels of soluble interleukin receptor antagonist levels (sIL-1RA), an anti-cytokine antagonizing the effects of IL- $1^{66}$. However, a more recent study showed that sIL-1RA levels, both at baseline and during glucocorticoid treatment, are neither influenced by cigarette smoking nor predictive of subsequent response to glucocorticoid treatment ${ }^{71}$.

\section{c. Chronic lymphocytic thyroiditis}

In a longitudinal study of randomly selected samples of women, Nystrom et $\mathrm{al}^{10}$ demonstrated a strong association between smoking 12 years earlier and the subsequent development of autoimmune hypothyroidism, while smoking habits at the end of the investigation were not related to hypothyroidism. This association, however, has not been confirmed in other studies ${ }^{13,36}$. As mentioned earlier, the prevalence of smokers was about $30 \%$ in patients with Hashimoto's thyroiditis, much lower than those with Graves' disease without (48\%) or with ophthalmopathy $(64 \%)^{36}$.

Although both Graves' disease and Hashimoto's thyroiditis are two inter-related autoimmune disorders and they represent the two sides of the same coin, it is very interesting that they show such diversity in their relation to tobacco smoking. Therefore, other factors, possibly unrelated to a direct action of smoking on the immune system, might be implicated in the connection between Graves' disease and smoking

\section{d. Pregnancy, fetal thyroid function and post- partum thyroid dysfunction}

A highly significant correlation has been demonstrated between SCN- levels in the mother and cord blood, a finding indicating that $\mathrm{SCN}$ - freely crosses the placen$\mathrm{ta}^{72}$. An inverse correlation was found between SCN- levels in cord blood, birth weight, significantly decreased serum TSH levels and increased T4 levels in newborn babies of smoking mothers compared to non-smoking ones.

Thiocyanate has a biological half-life of 1-2 weeks $^{27}$. Therefore, measurements in plasma may be used to detect the degree of exposure to smoking from days to weeks after the last consumption. Gasparoni et $\mathrm{al}^{27}$ found that infants whose mothers and fathers smoked had higher cord serum thyroglobulin and SCN- concentrations in comparison with infants whose parents did not smoke. The infants had no other evidence of thyroid abnormalities, such as increased T4,T3 or decreased TSH concentrations ${ }^{73}$. Although thyroid size was not determined in this study, it has been reported to be increased in infants born from mothers who smoked ${ }^{74}$. Of interest are two more findings from Gasparoni et $\mathrm{al}^{27}$. First, that cord serum $\mathrm{Tg}$ levels were increased in the infants whose fathers, but not mothers, smoked, which means that the components of cigarette smoking that stimulate $\mathrm{Tg}$ secretion can be passively transferred to the infants, and secondly, that at age one of their lives, the same infants whose both parents smoked had higher serum $\mathrm{Tg}$ and SCN-concentrations than the infants whose parents did not smoke. Thus, smoking seems to induce similar changes in thyroid function in adults and the fetus. However, the fetus is, theoretical, more affected by these changes in thyroid function. Thus, these alterations may contribute to the growth retardation seen in babies born to smoking mothers ${ }^{75}$.

The role of cigarette smoking in the development of post-partum thyroid dysfunction is not known. In a study of post-partum thyroid function in a group of 220 women, thyroid dysfunction was detected in $22 \%$ and was significantly related to smoking and to the presence of thyroid microsomal antibodies ${ }^{76}$. However, this finding has not been confirmed ${ }^{72,77,78}$.

\section{CONCLUDING REMARKS}

Based on recent available information, smoking exerts an influence on thyroid function through different mechanisms. Concerning thyroid hormone levels, smoking produces minor changes which are in general insignificant. The SCN- in smoke is most probably responsible for the goitrogenic action of smoking, especially in iodine deficiency areas.

There are some reports which have shown that smok- 
ing has a protective effect on the incidence of thyroid cancer. However, many more studies are needed to confirm this effect and elucidate its mechanism.

The association between Graves' disease and smoking, and particularly Graves' opthalmopathy and smoking, is much stronger and clearer. Smoking exacerbates thyroid eye disease and has a negative influence on the outcome of different therapeutic regimens and especially radioactive iodine. The mechanism is not yet fully understood. Regarding Hashimoto's thyroiditis and postpartum thyroiditis, no association with smoking has so far been disclosed.

\section{REFERENCES}

1. Christensen SB, Ericsson UB, Janzon L, Tibblin S, Melander A 1984 Influence of cigarette smoking on goiter formation, thyroglobulin and thyroid hormone levels in women. J Clin Endocrinol Metab 58: 615-618.

2. Hegedus L, Karstrup S, Veiergang D, Jacobsen B, Skoustad L, Feldt-Rasmussen U 1985 High frequency of goiter in cigarette smokers. Clin Endocrinol (Oxf) 22: 287-292.

3. Karakaya A, Tuncel N, Alptuna G Kocer Z, Erbay G 1987 Influence of cigarette smoking on thyroid hormone levels. Hum Toxicol 6: 507-509.

4. Lio S, Napolitano G, Mariuzzi G, Monaco F 1989 Role of smoking in goiter morphology and thyrotropin response to TRH in untreated goitrous women. J Endocrinol Invest 12: 93-97.

5. Petersen K, Lindstedt G, Lundberg PA Bengtsson C, Lapidus L, Hystrom E 1991 Thyroid disease in middle-aged and elderly Swedish women: Thyroid related hormones, thyroid dysfunction and goiter in relation to age and smoking. J Intern Med 229: 407-414.

6. Hegedus L, Bliddal, H, Karstrup S, Seck K 1992 Thyroid stimulating immunoglobulins are not influenced by smoking in healthy subjects. Thyroidol Clin Exp 4: 91-92.

7. Melander A, Nordenskjold E, Lunch E, Thorell J 1981 Influence of smoking on thyroid activity. Acta Med Scand 209: 41-45.

8. Eden S, Jagenburg R, Lindstedt G, Lundberg PA, Mellstrom D 1984 Thyroregulatory changes associated with smoking in 70 year-old men. Clin Endocrinol (Oxf) 21: 605-610.

9. Sepkovic DW, Haley NJ, Wynder EL 1984 Thyroid activity in cigarette smokers. Arch Intern Med 144: 501-503.

10. Nystrom E, Bengtsson C, Lapidus L, Lindstedt G 1993 Smoking - A risk factor for hypothyroidism. J Endocrinol Invest 16: 129-131.

11. Muller B, Zulewski H, Huber P, Ratcliffe JG, Staub J-J 1995 Impaired action of thyroid hormone associated with smoking in women with hypothyroidism. N Engl J Med 333: 964-969.

12. Utiger RD 1995 Cigarette smoking and the thyroid. N Engl J Med 333: 1001-1002.
13. Ericsson UB, Lindgarde F 1991 Effects of cigarette smoking on thyroid function and the prevalence of goiter, thyrotoxicosis and autoimmune thyroiditis. J Intern Med 229: 67-71.

14. Mc Tiernan A, Weiss NS, Daling JR 1984 Incidence of thyroid cancer in women in relation to reproductive and hormonal factors. Am J Epidemiol 120: 423-435.

15. Ron E, Kleinerman RA, Boice Jr JD, Li Volsi VA, Flannery JT, Fraumeni Jr JF 1987 A population-based casecontrol study of thyroid cancer. J Natl Cancer Inst 79: 112.

16. Kolonel LN, Hankin JH, Wilkens LR, Fukunaga FH, Hinds MW 1990 An epidemiologic study of thyroid cancer in Hawaii. Cancer Causes Control 1: 223-234.

17. Preston-Martin S, Jin F, Duda MJ, Mack WJ 1993 A casecontrol study of thyroid cancer in women under age 55 in Shangai (People's Republic of China). Cancer Causes Control 4: 431-440.

18. Shore RE, Hildreth N, Dvoretsky P, Andresen G, Moseson M, Pasernack B 1993 Thyroid cancer among persons given $\mathrm{x}$-ray treatment in infancy for an enlarged thymus gland. Am J Epidemiol 137: 1068-1080.

19. Hallquist A, Hardell L, Degerman A, Boquist L 1994 Thyroid cancer: reproductive factors, previous diseases, drug intake, family history and diet. A case-control study. Eur J Cancer Prev 3: 481-488.

20. Galanti MR, Hansson L, Lund E Bergstrom R, Grimelius L, Stalsberg H, Carlsen E, Baron JA, Persson I, Ekbom A. 1996 Reproductive history and cigarette smoking as risk factors for thyroid cancer in women: a populationbased case-control study. Cancer Epidemiol Biomarkers Prev 5: 425-431.

21. Rossing MA, Cushing KL, Voigt LF, Wicklund KG, Daling JR 2000 Risk of papillary thyroid cancer in women in relation to smoking and alcohol consumption. Epidemiology 11: 49-54.

22. Hallquist A, Hardell L, Degerman, Boquist L 1993 Occupational exposures and thyroid cancer: results of a casecontrol study. Eur J Cancer Prev 2: 345-349 .

23. Kreiger N, Parkes R 2000 Cigarette smoking and the risk of thyroid cancer. Eur J Canc 36: 1969-1973.

24. Prummel MF, Wiersinga WM 1993 Smoking and risk of Graves' disease. JAMA 269: 479-482.

25. Bartalena L, Bogazzi F, Tanda ML, Manetti L, Dell' Unto E, Martino E 1995 Cigarette smoking and the thyroid. Eur J Endocrinol 133: 507-512.

26. Bartalena L, Pinchera A, Marcocci C 2000 Management of Graves' ophthalmopathy : reality and perspectives. Endocr Rev 21: 138-169.

27. Gasparoni A, Autelli M, Ravagni-Probizer MF, Bartoli A, Regazzi-Bonora M, Chirico G, Rondini G 1998 Effect of passive smoking on thyroid function in infants. Eur $\mathrm{J}$ Endocrinol 138: 379-382.

28. Utiger RD 1998 Effects of smoking on thyroid function. Eur J Endocrinol 138: 368-369.

29. Salogiee Y, Vesey CJ, Cole PV, Russel MA H 1982 Carboxyhemoglobin and plasma thiocyanate complementary indicators of the smoking behavior. Thorax 37: 521- 
525.

30. Fukayama H, Nasu M, Murakami S, Sugawara M 1992 Examination of antithyroid effects of smoking products in cultured thyroid follicles: Only thiocyanate is a potent antithyroid agent. Acta Endocrinol (Copenh) 127: 520525.

31. Juske WJ 1979 Influence of cigarette smoking on drug metabolism in man. Drug Metab Rev 9: 221-236.

32. Bertelsen JB, Hegedus L 1994 Cigarette smoking and the thyroid. Thyroid 4: 327-331.

33. Cryer PE, Haymond M, Santiago JV, Shah SD 1976 Norepinephrine and epinephrine release and adrenergic mediation of smoking-associated hemodynamic and metabolic events. N Engl J Med 295: 573-577.

34. Hegedus L, Perrild H, Poulsen LR, Anderson JR, Holm B, Schnorr P, Jersen G, Hansen JM 1983 The determination of thyroid volume by ultrasound and its relationship to body weight, age and sex in normal subjects. J Clin Endocrinol Metab 66: 260-263.

35. Berghout A, Wiersinga WM, Smits NJ, Touber JL 1987 Determinants of thyroid volume as measured by ultrasonography in healthy adults in a non-iodine deficient area. Clin Endocrinol (Oxf) 26: 273-280.

36. Bartalena L, Martino E, Marcocci C, Bogazzi F, Pamicucci M, Velluzzi F, 1989 More on smoking habits and Graves' ophthalmopathy. J Endocrinol Invest 12: 733-737.

37. Jarlev AE, Hegedus L, Gjorup, Hansen JM 1991 Observer variation in the clinical assessment of the thyroid gland. J Intern Med 229: 159-161.

38. Jarlev AG, Hegedus L, Cjorup T, Hansen JM 1991 Accuracy of the clinical assessment of thyroid size. Dan Med Bull 38: 87-89.

39. Ermans AM, Mbulamoko NM, Delange F, Ahluwallak R 1980 Role of cassava in the etiology of endemic goiter and cretinism. International Development Research Center, Ottawa.

40. Schneider AB 1991 Carcinoma of follicular epithelium. In: Braverman LE and Utiger RD. Werner and Ingbar's The Thyroid. J B Lippincott Company, Philadelphia USA: 1121-1129.

41. Sokic SI, Adanja BJ, Vlajinac HD, Jankovic RR, Marinkovic JR, Zivaljevic VR 1994 Risk factors for thyroid cancer. Neoplasma 41: 371-374.

42. Fisher C, Mannino DM, Herman WH, Frumkin H 1997 Cigarette smoking and thyroid hormone levels in males. Int J Epidemiol 26: 972-977.

43. Ron E. Thyroid cancer. In: Schottenfeld D, Fraumeni JF Jr, eds. Cancer Epidemiology Prevention 2nd ed. New York, Oxford University Press, 1996; 1000-1021.

44. Baron JA, La Vecchia C, Levi F 1990 The antiestrogenic effect of cigarette smoking in women. Am J Obstet Gynecol 162: 502-514.

45. Dai WS, Gutai JP, Kuller LH, Canley JA 1988 for the MRFIT Research Group, 1998 Cigarette smoking and serum sex hormones in men. Am J Epidemiol 128: 796805.

46. Wiersinga WM 1999 Enviromental factors in autoimmune thyroid disease. Exp Clin Endocrinol Dis 107 (Suppl.3):
567-570.

47. Laurberg P, Pedersen KM, Hreidarsson A, Sigfusson N, Iversen E, Knudsen PR 1998 Iodine intake and the pattern of thyroid disorders: a comparative epidemiological study of thyroid abnormalities in the elderly in Iceland and in Jutland, Denmark. J Clin Endocrinol Metab 83: 765-769.

48. Wiersinga WM, Prummel MF, Strieder TG 2000 Environmental factors in healthy women at risk for autoimmune thyroid disease. In: Peter F, Wiersinga W, Hostalek U. The Thyroid and Environment. "Merck European Thyroid Symposium, Budapest 2000, June 22-25, Schattauer, Stuttgart, Germany, 179-184.

49. Tomer Y, Davies TF 1993 Infection, thyroid disease, and autoimmunity. Endocr Rev 14: 107-120.

50. Winsa B, Adami H-O, Bergstrom, Gamstedt A, Daheberg PA, Adamson U, Jansson R, Karlsson A 1991 Stressful life events and Graves' disease. Lancet 338: 1475-1479.

51. Chiovato L, Pinchera A 1996 Stressful life events and Graves' disease. Eur J Endocrinol 134: 680-682.

52. Paunkovic N, Paunkovic J, Panhovic O, Paunovic Z 1998 The significant increase in incidence of Graves' disease in Eastern Serbia during the civil war in the former $\mathrm{Yu}$ goslavia. Thyroid 8: 37-41.

53. Martino E, Bogazzi F, Pinchera A, Bartalena L 2000 Cigarette smoking and thyroid autoimmunity. In: Peter F, Wiersinga N, Hostalek U. The thyroid and Environment. "Merck European Thyroid Symposium" Budapest 2000; June 22-25, Schattauer, Stuttgart, Germany 145-154.

54. Winsa B, Mandahl A, Karlsson FA 1993 Graves' disease, endocrine ophthalmopathy and smoking. Acta Endocrinol (Copenh) 128: 156-160.

55. Tallstedt L, Lundell G, Taube A 1993 Graves' ophthalmopathy and tobacco smoking. Acta Endocrinol (Copenh) 129: 147-150.

56. Shine B, Fells P, Edwards OM, Neetman AP 1990 Association between Graves' ophthalmopathy and smoking. Lancet 335: 1261-1263.

57. Perkins KA, Grobe JE 1992 Increased desire to smoke during acute stress. Br J Addict 87: 1037-1040.

58. Heufelder AE 1998 T-cell restriction in thyroid eye disease. Thyroid 8: 419-422.

59. Krassas GE, Heufelder A 2001 Immunosuppressive therapy in patients with thyroid eye disease: an overview of current concepts. Eur J Endocrinol 144: 311-318.

60. Hagg E, Asplund K 1987 Is endocrine ophthalmopathy related to smoking? Br Med J 295: 634-635.

61. Pfeilschifter J, Ziegler R 1996 Smoking and endocrine ophthalmopathy: impact of smoking severity and current vs. lifetime cigarette consumption. Clin Endocrinol (Oxf) 45: 477-481.

62. Tellez M, Cooper J, Edmonds C 1992 Graves' ophthalmopathy in relation to cigarette smoking and ethnic origin. Clin Endocrinol (Oxf) 36: 291-294.

63. Bartalena L, Marcocci C, Tanda M, Manetti L, Dell' Unto E, Bartolomei MR, Nardi P, Martino E, Pinchera A 1998 Cigarette smoking and treatment outcomes in Graves' ophthalmopathy. Ann Intern Med 129: 632-635. 
64. Bartalena L, Marcocci C, Bogazzi F, Manetti L, Tanda ML, Dell' Unto E, Bruno-Bossio G, Nardi M, Bartolomei MP, Lepri A, Rossi G, Martino E, Pinchera A 1998 Relation between therapy for hyperthyroidism and the course of Graves' ophthalmopathy. N Engl J Med 338: 73-78.

65. Bartalena L, Marcocci C, Bogazzi F, Panicucci M, Lepri A, Pinchera A 1989 Use of corticosteroids to prevent progression of Graves' ophthalmopathy after radioiodine therapy for hyperthyroidism. N Engl J Med 321: 13491352.

66. Hofbauer LC, Muhlberg T, Konig A, Heufelder G, Schword H-D, Henfelder AE 1997 Soluble interleukin-1 receptor antagonist serum levels in smokers and nonsmokers with Graves' ophthalmopathy undergoing orbital radiotherapy. J Clin Endocrinol Metab 82: 2244-2247.

67. Heufelder AE 1995 Pathogenesis of Graves' ophthalmopathy: recent controversies and progress. Eur J Endocrinol 132: 532-541.

68. Krassas GE, Pontikides N, Doukidis D, Heufelder G, Heufelder AE 2001 Serum levels of tumor necrosis factor- $\alpha$ (TNF- $\alpha$ ), soluble intercellular adhesion molecule1 (sICAM-1), soluble vascular cell adhesion molecule-1 (sVCAM-1) and soluble interleukin-1 receptor antagonist (sIL-1RA) in patients with thyroid eye disease undergoing treatment with somatostatin analogues. Thyroid 11 (12): 1115-1122.

69. Metcalfe RA, Weetman AP 1994 Stimulation of extraocular muscle fibroblasts by cytokines and hypoxia: possible role in thyroid-associated ophthalmopathy. Clin Endocrinol (Oxf) 40: 67-72.

70. Heufelder AE, Bahn RS 1992 Modulation of intercellular adhesion molecule-1 (ICAM-1) by cytokines and Graves' IgGs in cultured Graves' retroocular fibroblasts.
Eur J Clin Invest 23: 10-17.

71. Bartalena L, Manetti L, Tanda ML, Dell' Unto E, Mazzi B, Rocchi R, Barbesino G, Pinchera A, Marcocci C 2000 Soluble interleukin-1 receptor antagonist concentration in patients with Graves' ophthalmopathy is neither related to cigarette smoking nor predictive of subsequent response to glucocorticoids. Clin Endocrinol (Oxf) 52: 647651.

72. Ohtman S, Phillips DIW, Parkes AB, Richards CJ, Harris B, Fung H, Lazarus JH 1990 A long-term follow-up of postpartum thyroiditis. Clin Endocrinol (Oxf) 32: 559-564.

73. Meberg A, Marstein S 1986 Smoking during pregnancy effects on fetal thyroid function. Acta Paediatr Scand 75: 762-766.

74. Chanoine JP, Toppet V, Bourdoux P, Spehl M, Delange F 1991 Smoking during pregnancy: a significant cause of neonatal thyroid enlargement. Brit J Obstet Gynaecol 98: 65-68.

75. Rubin DH, Krasilnikoff P, Leventhal JM, Weile B, Bergei A 1986 Effect of passive smoking on birth-weight. Lancet 4: 415-417.

76. Fung HYM, Kologlu M, Collison K, John R, Richards C, Hall R, McGregor AM 1988 Postpartum thyroid dysfunction in Mid Glamorgan. Br Med J 296: 241-244.

77. Rasmussen N, Hornnes PJ, Feldt - Rasmussen U, Haier Medsen M, Hegedus L 1990 Thyroid size and function in healthy pregnant women with thyroid autoantibodies. Relation to development of postpartum thyroiditis. Acta Endocrinol (Copenh) 23: 395-401.

78. Tachi J, Amino N, Tamaki H, Adzasa M, Iwalani Y, Hiyai K 1988 Long term follow-up and HLA association in patients with postpartum hypothyroidism. J Clin Endocrinol Metab 66: 480-484 